\title{
Identifying Critical Causes for Lead Time in Order Processing of Freight Forwarding Supply Chain
}

\author{
S.Rajakumar ${ }^{1}$, R.Prasanna Sudarsanan ${ }^{2}$ \\ ${ }^{1}$ Department of Mechanical Engineering \\ Sree Sakthi Engineering College, Karamadai, Coimbatore, Tamilnadu, India \\ ${ }^{2}$ Aachi Masala Foods Pvt. Ltd, Chennai, Tamilnadu, India
}

\begin{abstract}
The lead time of order processing plays a major role in air freight forwarding supply chain. The lead time of each order differs due to number of causes existing in the company. The major possible causes are identified for consideration. Pareto analysis is carried out to find out the causes for majority of lead time problems. Finally, four critical causes are short listed for optimizing the order process by reducing order delay or lead time.
\end{abstract}

Keywords: lead time, supply chain, Pareto analysis, freight forwarding

\section{INTRODUCTION}

The global business environment is influenced by globalization, strategic alliances, merger and acquisition and business process reengineering. In recent scenario the success of any business is measured based on spread of supply chain. The typical supply chain starts from gathering of raw materials or goods and finishes with goods supplied to the end user. The freight forwarders play an important role in logistical aspect of supply chain. The freight forwarding and logistics services affect services associated with the carriage, consolidation, storage, handling, packing or distribution of products also as ancillary and advisory services including customs and monetary matters. In supply chain, an order process plays an important role in connecting the customer and supplier. The supplier works based on the customer order as the source of information and works to fulfill the order. The most important part here is the information flow. The efficiency of the process, cost and lead time are all based on the information provided. Inaccurate and improper information may lead to increased lead time, high cost, high level of inventory, wastage of resources etc.

This research is conducted on the operations of freight forwarding industry particularly air exporting function of a company. The major function in a freight forwarding industry is the order processing. Any business done in the company is based on the customer order. The customer order comes in the form of enquiry. The order processing involves a sequence of processing to do the shipment. Each order is unique and separate in its own way. So, the planning for each order process differs. It becomes essential for the company to process each order with its prerequisite so that there is no difficulty in the shipment of the consignment. It is not an easy process as each order has its own lead time in processing the order cycle. The amount of lead time distribution has to be computed in order to optimize the process. It is decided to investigate the causes for the lead time in the process and the solutions are to be found out to optimize the lead time. In this study, an attempt is made to find out possible causes that lead to increase in lead time which results in order delay. The sample data were collected and analyzed to find out lead time distribution available in the order processing. The probable causes for lead time presence in order processing were identified by discussions with stake holders of the process. The major contributing causes for the lead time were identified by using Pareto analysis. 


\section{LITERATURE REVIEW}

The dynamics of changes occurring on local and global markets connected with more and more complex processes accompanying international trade transactions has stimulated the growth of forwarding companies. A strong need of adjustment of offered forwarding needs, adaptation to the requirements and growing demands of companies (clients) and the need to adapt to the changing conditions were the causes of further evolution of forwarding companies [1]. Gunasekaran [2] had pointed out that fundamental to any logistics strategy is the minimization of the costs of transportation, warehousing, inventory, and order processing while achieving the desired level of customer service. Choy et al. [3] described the generic order fulfillment process and it is important to provide responsive customer service while keeping a close relationship with customers and suppliers. The more effective and robustly the operation process can be linked, the deeper integration with customers and partners can be achieved and the greater value can be delivered. It could also results in loss, duplication, incorrect distribution or unauthorized disclosure of business information. Mallikarjun et.al [4] considered Fish Bone Diagram and Pareto Chart to identify the causes and provide solutions to recurring incidents by reducing the productivity loss. Ha et.al [5] considered the cargo scheduling model as shipments assignment model which assigns shipments to available flights based on both spot market prices and allotment contract prices. The short lead time between order and delivery times contributes towards the systemic optimization of entire supply chain network [6]. The lead time is the key operational performance indicator in the design of supply chain [7]. The performance indicator of a logistics system is the daily freight turnover rate [8]. Kumar [9] identified seven risks while analyzing the supply chain risk issues for an Indian manufacturing company using Pareto analysis. Chanchaichujit et al.[10] illustrated that the Pareto solutions may be used to design new supply chain. From the review it is evident that lead time optimization has to be addressed for order processing in a supply chain.

\section{METHODOLOGY}

The order processing has five steps: order preparation, order transmittal, order entry, order filling and order status reporting. The sample data for 135 orders that happened over a period of three months collected and the following observations were made. The table 1 shows the distribution of mode of order received by the operation team of the company. Even though many modes are available, 4 major modes are shortlisted for consideration.

Table 1. Mode of order

\begin{tabular}{|c|l|c|}
\hline S.No & Mode of order & Percentage \\
\hline 1 & Phone Call & 20 \\
\hline 2 & e-mail & 40 \\
\hline 3 & Client site representative & 15 \\
\hline 4 & Posts & 25 \\
\hline
\end{tabular}

Table 2. Lead time distribution in days

\begin{tabular}{|c|c|c|}
\hline Lead time in days & Number of orders & Percentage of orders \\
\hline $1-5$ & 65 & $48 \%$ \\
\hline $6-10$ & 20 & $14 \%$ \\
\hline $11-20$ & 21 & $15 \%$ \\
\hline $21-50$ & 15 & $12 \%$ \\
\hline$>51$ & 14 & $11 \%$ \\
\hline
\end{tabular}

Table 2 shows the relation between lead time and number of orders from customers and quotations prepared by the operations team. One important challenge faced during this process is, as we know most of the orders are placed in the form of calls and e-mails. The operations team undertook the process through mail without creating order number. The enquiry will be get systemized only by creating the order number. The actual process requires the operations team to respond only to the systematized enquiries but the operations team process the order 
in mails and calls and then only systemizes, before sending the actual quotation. It is understood that $48 \%$ of orders were completed in about five days. It is evident that most of the orders were processed in a span of five days. Then about $14 \%$ orders took a lead time up to 10 days. $15 \%$ orders have a lead time of 29 days and $23 \%$ of orders have a lead time of above 20 days. It is evident that nearly $52 \%$ of orders were processed with a maximum lead time of 10 days. The above data analysis shows that it is essential to reduce the lead time to increase the productivity of the company.

\section{CAUSES FOR LEAD TIME}

The lead time is measured in terms of days from enquiry stage to final order preparation. Each order is unique that are coming into the company as enquiry. Each order has its own lead time in processing the final order cycle. The amount of lead time in the process has to be studied in order to find out the causes for the delay. The probable causes for lead time were identified through discussions held with all stake holders of the company and they are listed in the table as shown below:

Table 3. Causes for lead time

\begin{tabular}{|l|l|}
\hline S.No & \\
\hline 1 & Rates not matching the customer needs \\
\hline 2 & Airlines space not available or available only for a later date \\
\hline 3 & Difficulties due to consignment dimensions \\
\hline 4 & Enquiring in advance \\
\hline 5 & Embargo destination \\
\hline 6 & Natural calamities \\
\hline 7 & Change in time zone between countries \\
\hline 8 & Bulk orders \\
\hline 9 & Non Systemization of enquires \\
\hline 10 & Conversation with the airline operators \\
\hline 11 & Delay in preparation of quotation \\
\hline 12 & Export documents \\
\hline 13 & Errors in data \\
\hline
\end{tabular}

\section{EXPERIMENTATION USING PARETO ANALYSIS}

Pareto Principle otherwise called as 80-20 rule was derived by an Italian economist Vilfredo Pareto. The 80-20 rule states that $80 \%$ of effects are coming from $20 \%$ of causes. By the way Pareto analysis is used to allocate scarce resources. It is important to note that this tool is wholly based on recommended actions of present data. The Pareto chart is a visual representation of the vital few against the trivial many. With the help of the chart it is easy to identify the causes for most of the problems. Table 4 is prepared by using following two criteria to draw the Pareto Chart.

1. Arrange the causes in descending order based on importance.

2. Calculate the cumulative count and percentage for each cause in descending order. 
Volume: 3 Issue: 5

Table 4. Causes considered for Pareto analysis

\begin{tabular}{|l|l|c|c|c|}
\hline NO. & Causes & Count & Cumulative Count & $\begin{array}{l}\text { Cumulative } \\
\text { Percentage }\end{array}$ \\
\hline 1 & Non Systemization & 25 & 25 & 18.52 \\
\hline 2 & Rates not matching & 20 & 45 & 33.33 \\
\hline 3 & Export Documents & 18 & 63 & 46.67 \\
\hline 4 & Error in data & 18 & 81 & 60.00 \\
\hline 5 & Quotation & 14 & 95 & 70.37 \\
\hline 6 & Bulk order & 10 & 105 & 77.78 \\
\hline 7 & Space not available & 9 & 114 & 84.44 \\
\hline 8 & Dimensions not matching & 8 & 122 & 90.37 \\
\hline 9 & Time Zone & 7 & 129 & 95.56 \\
\hline 10 & Advance booking & 6 & 135 & 100.00 \\
\hline
\end{tabular}

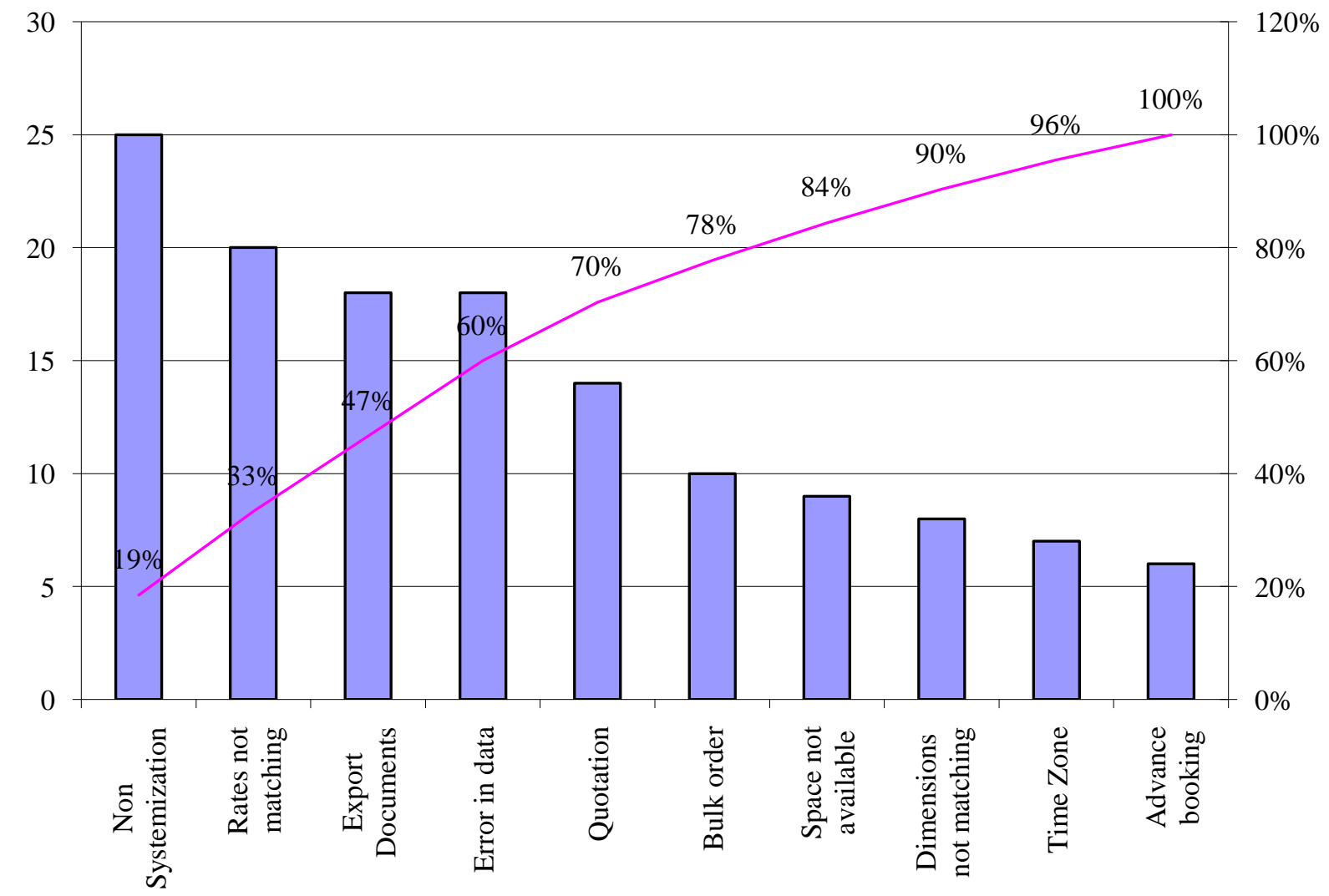

Figure 1. Pareto Chart

With the given data, American Society for Quality (ASQ) tools and templates are used to draw Pareto chart to determine the vital causes for the lead time. From, the Pareto chart we can note that $80 \%$ lies between the causes of non systemization of enquiries to bulk order booking. So, by concentrating on the above causes and solving those with new methods may have positive effects on overall process. 


\section{RESULTS AND DISCUSSIONS}

The research work is made as an attempt to study the operational functions of air exports division in a company. It was found that there were more lead time accumulations in each and every order processed in the order processing system of the company. It was decided to precede the work on optimization of lead time in order processing. The sample data for the work were acquired from the ERP system of the company. The probable causes for the lead time optimization in order processing were listed out after many discussions and interviews with the employees. Two (2) causes namely embargo destination and natural calamities were left out for consideration as because they are unavoidable if occurred among thirteen (13) as shown in the table. The Pareto analysis was carried out to find out the most critical causes constituting the $80 \%$ of the problem of lead time accumulations. Among ten causes (10), six (6) causes were listed out as the most critical. From the list, four causes namely non- systemization, rates not matching the customer needs, export documents and errors in data contribute almost for $60 \%$ of the problem. The root causes for the problem were identified by conducting the Pareto analysis.

\section{Conclusion}

The causes for lead time in the ordering process of air exports division were identified using Pareto analysis. As outcome, four cases out of thirteen possible causes are short listed to optimize the lead time mentioned. The productivity of the company will be improved by concentrating on the above four issues. This work may be extended further to study about the framework for implementing and integrating the IT tools with the existing ERP system of the company.

\section{REFERENCES}

[1] Bhatnagar, R., Viswanathan, S., "Reengineering global supply chains: Alliances between manufacturing and global logistics service providers", International Journal of Physical Distribution and Logistics Management,Vol.30 (1), pp.13-34, 2000.

[2] Gunasekaran, A., "3PL: experiences from China resources logistics (Hong Kong)", Int. J. of Logistics Systems and Management Vol.1, pp.81- 97, 2004.

[3] K.L. Choy, Chung-Lun Li, Stuart C.K. So, Henry Lau, S.K. Kwok, Dennis W.K. Leung, "Managing uncertainty in logistics service supply chain", Int. J. of Risk Assessment and Management, Vol.7, No.1, pp.19 - 43, 2007.

[4] Mallikarjun K., Venkata Subbaiah K.(2014). Problem Solving Management Using Six Sigma Tools \& Techniques, International Journal of Scientific \& Technology Research Volume 3, Issue 2, February 2014.

[5] Ha, Hai Thi Hong; Nananukul, Narameth, "Air Cargo Optimization Models for Logistics Forwarders", Advanced Science Letters, Volume 23, Number 5, , pp. 4162-4167(6), May 2017.

[6] M. Grazia Speranza, "Trends in transportation and logistics", European Journal of Operational Research, 2016, http://dx.doi.org/10.1016/j.ejor.2016.08.032

[7] Ivanov, D., "Disruption tails and revival policies: A simulation analysis of supply chain design and production-ordering systems in the recovery and post-disruption periods", Computers \& Industrial Engineering, 2018, doi: https://doi.org/10.1016/j.cie.2018.10.043

[8] Elena Panfilova1, Natalia Dzenzeliuk2 , Olga Domnina3 , Natalia Morgunova 4, Elena Zatsarinnaya, "The Impact of Cost Allocation on Key Decisions of Supply Chain Participants", International Journal of Supply Chain Management IJSCM, ISSN: 2050-7399 (Online), 2051-3771 (Print) Vol. 9, No. 1, February 2020, 552-558

[9] Kumar Pradhan, S. and Routroy, S. "Analyzing the supply chain risk issues for an Indian manufacturing company", Journal of Advances in Management Research, 2014, Vol. 11 No. 2, pp. 144-162. https://doi.org/10.1108/JAMR-11-2012-0047

[10] Chanchaichujit, J., Balasubramanian, S., \& Shuka, V. "Multi-objective decision model for green supply chain management" Cogent Business \& Management, 7(1), 1783177, 2020. https://doi.org/10.1080/23311975.2020.1783177. 